\title{
Assessing the Impact of Engagement and Real- Time Feedback in a Mobile Behavior Change Intervention for Supporting Critical Thinking in Engineering Research Projects
}

\author{
Yousef A. Asiri, David E. Millard, and Mark J. Weal
}

\begin{abstract}
Digital behavior change interventions (DBCIs) provide customized advice, ongoing support, and web- and mobile-based platforms for learners who want to change their undesirable behaviors. DBCIs have been successful in the past for delivering interventions which support sustained changes to health behaviors, such as disease prevention and health promotion. During research tasks, university students can require interventions associated with critical thinking skills and behaviors. By using a DBCI, educators can assist students with improving their learning skills in research projects. This study aims to understand student interactions and engagement with mobilebased DBCIs with the objective of improving their critical thinking skills. An experimental group was used to explore the effects of students' interactions with an engaging mobile-based DBCI with real-time feedback, and was designed using the LifeGuide Toolbox platform which supports their critical thinking skills over a period of two months whilst they conduct a research project. A comparison between formative expert assessments and self-reported evaluation was also performed. This experiment reveals that using a DBCI to encourage critical thinking skills within a research project context can significantly improve engagement with intervention components, as well as recommend areas which require further exploration where specific critical thinking skills and digital interventions components are the most promising.
\end{abstract}

Index Terms-Critical thinking, digital intervention, humancomputer interaction design, mobile learning, research projects.

\section{INTRODUCTION}

$\mathrm{C}$ RITICAL thinking is used by university students to perform an analysis, assessment and evaluation of the arguments in their research projects [1]-[3]. These research projects examine specific problems and potential solutions supported by reliable evidence [4]. Research projects stimulate students to ask questions and therefore derive more reliable information so that the problems can be better understood. In a research project, students practice and learn how to analyze,

Manuscript received November 1, 2019; revised March 18, 2021; accepted xxxxxx. Date of publication xxxxx; date of current version July 14, 2021.

Yousef A. Asiri was with Electronics and Computer Science Department, University of Southampton, Hampshire, SO17 1BJ U.K. He is now with the Computer Science Department, Najran University, Najran 61441 SA (e-mail: yasiri@nu.edu.sa). assess, and evaluate arguments, whilst simultaneously cultivating critical thinking skills, allowing them to handle real world issues [5], [6]. Generally, assistance and support is provided to students through research project supervision, and in-person meetings are the usual way in which research project supervisors and students communicate [7], [8]. Therefore, technology can be used to overcome communication barriers, for example place and time, alleviating some of the communication difficulties arising between supervisors and students [9].

During research projects students should be supported and assisted with their critical thinking skills by customizing information based on their own critical thinking abilities [10]. When delivering critical thinking and pertinent advice to students, the technical tools used must have compatibility with critical thinking [11], [12]. These tools should be designed carefully to improve the individual and the behavioral learning experiences in a critical thinking context. Many previous attempts have been employed to utilize technology to encourage critical thinking skills in various environments. For example, one study examined the use of an online learning environment when using collaboration to teach critical thinking [14]. Similarly, another experiment assessed the aspects which influence students' critical thinking skills when participating in online activities [15]. However, university students can lack the necessary critical thinking skills during their research projects [16]-[18]. There are many gaps in the research literature for using technology to develop critical thinking skills, which explains the scarce supportive environment for developing critical thinking. Firstly, a complete definition of critical thinking covering every aspect of critical thinking must be identified, just as a lifetime behavioral skill also requires enough time to develop [19], [20]. Secondly, there is little research which has examined both critical thinking and research projects, although the research which has been done is relatively associated with the tasks [3], [10]. Finally, well-

David E. Millard is with Electronics and Computer Science Department, University of Southampton, Hampshire, SO17 1BJ U.K. (e-mail: dem@soton.ac.uk).

Mark J. Weal is with Electronics and Computer Science Department, University of Southampton, Hampshire, SO17 1BJ U.K. (e-mail: mjw@ecs.soton.ac.uk). 
tested, suitable authoring tools should be developed to assist the supervisors with less technical knowledge to produce mobileor web-based interventions to evaluate student behavior and progress during critical thinking skill development [9], [16]. The tools which are available tend to be fixed and inflexible, making them difficult to use on a larger scale in different iterations with randomization, or for useful data collection.

This study postulates that using digital DBCI methods may offer relevant technical help to students in developing research skills and critical thinking. DBCIs are methods for providing customized advice and ongoing support via web- and mobilebased platforms (Fig. 1) for those who want to change undesirable behaviors [21]. Haghparast et al. [12] argued that using current mobile technology may be able to associate critical thinking skills and behavior. Mobile devices can be used to intervene and assist students with positively changing their critical thinking behaviors in their research [22], [23].

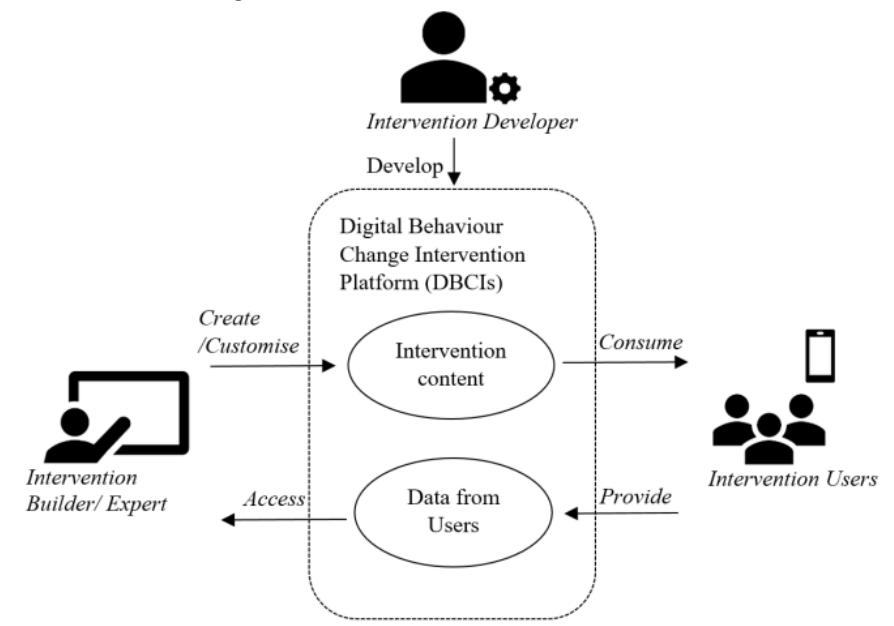

Fig. 1. DBCI components.

This study aimed to use mobile technologies as intervention tools as a result of their distinct personalization features, portability, connectedness, and flexibility [24]. Mobile technology affects many aspects of our lives, from education and work to social communication and personal interactions [25], [26]. From this perspective, critical thinking is an important daily activity with which mobile technology could assist users, and specifically students, to acquire intervention support, monitor any decisions taken, alter behavior, and assess the progress of reasoning patterns by using constant reminders, observations, and goals, at any location at any given time. Using DBCI systems in a blended context could affect education in several ways. Firstly, the system enables students to structure, shape, and influence their acquiring and learning approach and may motivate communication. Secondly, DBCIs could help teachers with selecting and developing online resources and changing traditional teaching methods. Third, for researchers and institutions, DBCIs offer large datasets for analysis, which can be used to conduct deeper investigations of learner behavior and learning processes.

The main objective of this research was to evaluate the usability and efficacy of DBCIs on the development of critical thinking behaviors in engineering students who are undertaking a research project. The intention is to scrutinize the impacts of using an application-based DBCI to improve critical thinking skills in the research projects of students and whether these improvements are associated with engagement in the mobile intervention components. To achieve this objective, two research questions were proposed: 1) What are the intervention components required to effectively use a digital mobile-based behavior change intervention (mBCI) to improve students' critical thinking skills and their engagement with the intervention? 2) How can students' critical thinking skills in their research project be improved by using a digital $\mathrm{mBCI}$ with real-time feedback?

Results from previously conducted preliminary pilot studies using mBCI to promote critical thinking skills revealed useful and interesting results. As a result of the outcome of the literature review, initial survey, interviews with academics, and the first pilot experimental study, these results demonstrate that mBCIs can potentially be an effective tool [17], [22]. Several alterations were implemented based on previous research to improve the evaluation process of adopting an $\mathrm{mBCI}$ in promoting critical thinking skills. Previous pilots did not include a comprehensive method to examine which factors may affect the outputs of using a digital mBCI. Consequently, this study performed an analysis of the intervention's usability, interaction with the intervention in real-time feedback, and engagement with the intervention components. In addition, expert reviews for evaluating participants' work were included to compare self-reported assessments made by students and the expert reviews after the experiment.

The contributions of this study are, first, to develop design principles to implement and test digital $\mathrm{mBCI}$ for the enhancement of critical thinking skills in a research project context with a formative assessment, and secondly, to study the engagement with each intervention component with real-time feedback to improve specific critical thinking standards and studying and evaluating various elements. As far as we are aware, no generic framework exists that has used DBCIs to assess feedback, and measure and support critical thinking skills in a research project context. By adjusting and facilitating the LifeGuide Toolbox, this research provides technical and design-knowledge contributions to the development of learning technologies.

\section{BACKGROUND}

Technology has had a real influence on all areas of our lives. Critical thinking is an important factor which technology has improved [27]. For instance, online discussion forums are designed to facilitate students and educators to collaborate to enrich their educational critical thinking skills [28]. Learners are able to discuss numerous topics, share thoughts, brainstorm ideas, evaluate each other across multiple aspects, and interact with different views. These forums allow learners with different goals and from different majors to apply their thinking in a generic context [3]. Indeed, digital learning interventions than make use of web- or mobile-based technology could be used for the promotion of critical thinking skills. Alnuaim et al. [14] adopted mobile technologies as contextual devices to foster interaction design skills, stating that there are notable findings which can be attributed to specific distinct features, for instance personalization, real-time feedback and interactions, and 
connectedness, which can be incorporated into daily tasks. The outcomes can be linked to ubiquitous learning-that is, being able to learn whenever and wherever - and are, consequently, closely connected to the affordability of mobile technology. The portability of computing technologies allows the bridging of differences between informal and formal learning, especially regarding the support of critical thinking skills. The current use of web-based platforms in schools and higher education settings includes online forums to enable collaboration and improve students' critical thinking skills educators [28]. Educators have also employed generic online tools for designing specific learner content, such as Facebook pages, Google documents, and massive open online course (MOOC) platforms [29]. These are flexible in their environmental settings and designs, permitting educators to create groups easily, promote group discussion, and deliver messages. Likewise, mobile apps have been used to engage learners and educators in the design of open learning environments (OLEs).

\section{A. Research Supervision in Online Learning Environments}

Critical thinking must be achieved by students when a project involves research-based tasks [30]. Using critical thinking skills is important at all stages of a research project. Students should remain aware of the effects of the critical thinking process and consider these implications over the course of their project. Norouzi et al. [31] demonstrated that students had a deficit of critical thinking and how it should be applied in practice, particularly in a research-based project context. It was also noted that students exhibited some disengagement during the research projects [9]. Thus, behavioral and cognitive support needs addressing, and should be able to maintain engagement and activity amongst students in their research process.

Using technology can help students to practice their skills, and well-designed technologies can assist students with overcoming any obstacles presented by location and time. An academic advisor is assigned to each student so that they can be mentored, supported, and guided in their research project. Yet, students who only improve their critical thinking skills via classes, lessons or supervisor meetings find this to be unhelpful and cost-ineffective [8]. Students require continual assistance during their research projects and often require guidance towards relevant information. As well as the benefits of working on research projects, students can face several challenges. For instance, undergraduate students usually only have a fundamental knowledge of research-based learning [32]. Students and their supervisors usually only meet in person. When this cannot be done, interaction usually takes place via basic tools, such as email, audio recordings [33], or Skype [34]. Some students and supervisors are familiar with other tools which facilitate them with maintaining contact, such as online supervising tracking systems [35]. These permit both supervisors (with limited technical or programming knowledge) and students to flexibly and easily collaborate in regard to place and time. Although the systems are limited in terms of their settings, the interface design cannot always adjust to the required content and format. The problems with the tools currently used can be resolved using the suggested frameworks and tools in this research, enabling supervisors and students to communicate effectively and easily.

\section{B. Assessment and Measurement of Critical Thinking in Research Projects: Paul-Elder Critical Thinking Framework}

The assessment of critical thinking skills should not be regarded as a simple task, and often requires different, regular and effective assessments; indeed, the majority of standardized tests which examine critical thinking skills are considered insufficient [36], including the Cornell Critical Thinking (CCT) Test, the Watson-Glaser Critical Thinking Appraisal (WGCTA), and the California Critical Thinking Skills (CCTS) Test, all of which use pre- and post-tests featuring multiple choice questions for assessing critical thinking abilities. Ennis [36] states that this approach may not provide accurate and useful data and that, although some factors can be measured, they are unable to tell us about the reasoning for specific answers. The issue with some of the instruments used to measure critical thinking is that they do not separately collect data for the different aspects or contexts of critical thinking. Each critical thinking element should be individually measured, after which there should be an examination of the process context to determine the progress of the development, particularly in a research project context [37]. Evaluating and measuring critical thinking skills can be performed using standard and non-standard tests, in accordance with the criteria for assessing critical thinking skills [36]. Crucially, the evaluation and appraisal of critical thinking skills should not depend on only one assessment tool, but needs to include several measures of skill, knowledge, behavior, and attitude [14].

The Paul-Elder Critical Thinking model is effective for demonstrating the essence of critical thinking [38], [39], and consists of 3 main parts: (1) elements of thought required for critical thinking, known as the scientific research stages; (2) nine intellectual thinking standards (accuracy, breadth, clarity, depth, fairness, logic, precision, relevance, and significance); and (3) the intellectual merits which make critical thinking, both behavioral and habitual [40]. The first component in the application of this framework is learning to recognize the thought elements (purpose in reasoning, questioning the issue, assumptions, interpretations, information, points of view, concepts, and the implications drawn from reasoning). The Paul-Elder Critical Thinking Framework [20] was used to assess and measure critical thinking skills throughout the different experiments in this research. This was for several reasons. Firstly, critical thinking is a behavior which can be subject to observation, and which changes over time [12], [18] although it may require a long period to occur. Secondly, critical thinking can be divided into several elements and standards, which permits each of these standards and elements to be separately evaluated [19], [41]. Thirdly, this framework is adopted in the context of research-based engineering projects to assess critical thinking skills.

The design of the survey-based instrument (Table I) was performed on the Paul-Elder Critical Thinking Framework. This was verified by academic supervisors with previous 
experience in supervising research projects and helping students develop critical thinking skills [17]. The instrument was improved during the entirety of the study, and the final version is presented in this paper. The final survey-based instrument version was utilized in both prior and later assessments to measure the development and progression of critical thinking skills across the duration of students' research engineering projects.

\section{Digital Behavior Change Interventions (DBCIs) for Critical Thinking}

DBCIs are methods applied when providing the learner with continual support and tailored guidance, with the objective of altering unwelcome behaviors through interactions with weband mobile- based platforms [42], [43]. A digital intervention is comprised of three factors, as shown in Fig. 1. Firstly, the intervention builders supply the necessary tools for users and intervention experts to digitally interact through web- or mobile-based platforms. Secondly, the intervention specialists, who may not have the essential technical or programming background, can design interventions that positively change the user's behavior. Thirdly, the intervention users obtain expert interventions by utilizing the platforms in mobile or web applications. then customizes the feedback is subsequently provided to the end-users.

Conventional interventions have been used in an educational setting to assist students with their studies or disabilities [47]. Vainio et al. [48] and Mooney et al. [49] state that several learning approaches have been employed as intervention strategies. For example, self-monitoring, self-reporting, and self-regulation, can indicate that students require behavioral or educational support. Their methods refer to self-generated thoughts, actions, emotions and attitudes, behaviors, and beliefs that are planned and can be used to improve student academic work. Thus, interventions can also be used for self-reporting and reflection by students on their perception of a scenario [50]. Interventions can have a major role in how learners approach challenges, tasks, and goals [49].

\section{METHODOLOGY}

The aim of the experiment was to examine the use of $\mathrm{mBCI}$ on students' critical thinking skills while conducting a research project. The study included online questionnaires before and after the intervention to measure and examine student views of their critical thinking skills, on the basis of the participant's self-reflections both prior to and after using the CriticalThinking application-based intervention; the

TABLE I

An Instrument for Measuring Critical Thinking Skills in Research Projects

Elements of Thought

Due to the increased acceptance of smartphones, DBCIs have now been produced in the form of mobile apps [44], which can enhance the level of customization by using contextual data obtained from phone-embedded sensors. Lathia et al. also explored this combination of DBCI applications with the sensing ability of the smartphone [45]. A personal health application for smartphones by [46] used sensors, including GPS, an accelerometer, and digital compass to autonomously examine the personal activities of end users, such as their general wellbeing, sleep, and physical activity. The application
1) Purpose: I think decisively when setting my research goals and attempt to answer the main question of my work and the reasons for its importance.

2) Questions: My research questions are used to guide my thinking to determine how the research problems can be solved.

3) Information: The information used is relevant and accurate in regard to the questions being addressed.

4) Inferences: The conclusions and inferences I make follow logically from the evidence, and only consider the implications of the situation.

5) Concepts: I utilize concepts, hypotheses, ideas, laws, principles, or theories justifiably in my thinking to make sense of the elements of my research work.

6) Assumptions: I ensure that my assumptions, subconscious or unconscious, are justified by the evidence.

7) Point of view: I am aware of the limitations of my perspective in my research work, and take into consideration other pertinent perspectives. 8) Implications: I retain an awareness of the implications of my claims and that they follow the logic of other truths or claims, where consequences follow from actions and implications follow from thoughts.

development of which was based on the LifeGuide Toolbox design principles framework. The survey-based instrument (Table I) used to measure critical thinking was used both before and after the intervention. The design of the study was validated in two previous studies by Asiri et al. [17], [22]. Here, students were required to use an $\mathrm{mBCI}$, with mobile notifications, for two months in their 3rd-year research projects with real-time feedback from the researchers. Quantitative data were collected from pre- and post-intervention online surveys so that the perceived progress of students' critical thinking skills could be examined, as well as to examine the impact of adopting the 
mBCI. Additionally, qualitative collected $\mathrm{mBCI}$ data and the participants' research reports were gathered and analyzed.

There are differences between the previous studies [17], [22] and this study in the methodology. For example, the previous experiment lacked a control group, which should be included in any human-computer interaction study, to control for potential external factors. Therefore, a control group was included in this study to evaluate whether any observed improvements could be reasonably attributed to the mobile intervention tools. In the previous experiment, self-reflections were the only inputs considered when evaluating the perceived improvements in critical thinking, which may have resulted in subjective assessments, as addressed by Alnuaim et al. [62]. In this experiment, academics and experts were also asked to assess the critical thinking skills displayed by participants in the submitted work (research reports and mobile texts).

\section{A. An mBCI Experimental Study}

Two stakeholders for the digital $\mathrm{mBCI}$ were considered: the intervention creators and the intervention users. Each stakeholder must perform specific tasks to achieve the digital $\mathrm{mBCI}$ requirements. Fig. 2 shows that the intervention creator has the responsibility for four steps (darker rectangles): these measure the user's skill level, design the intervention, support the user, evaluate the user's work, and provide feedback to the user. Intervention users are in charge of the following four steps: reflections on their own skills, interactions with the intervention components, intervention engagement, and positive behavioral change.

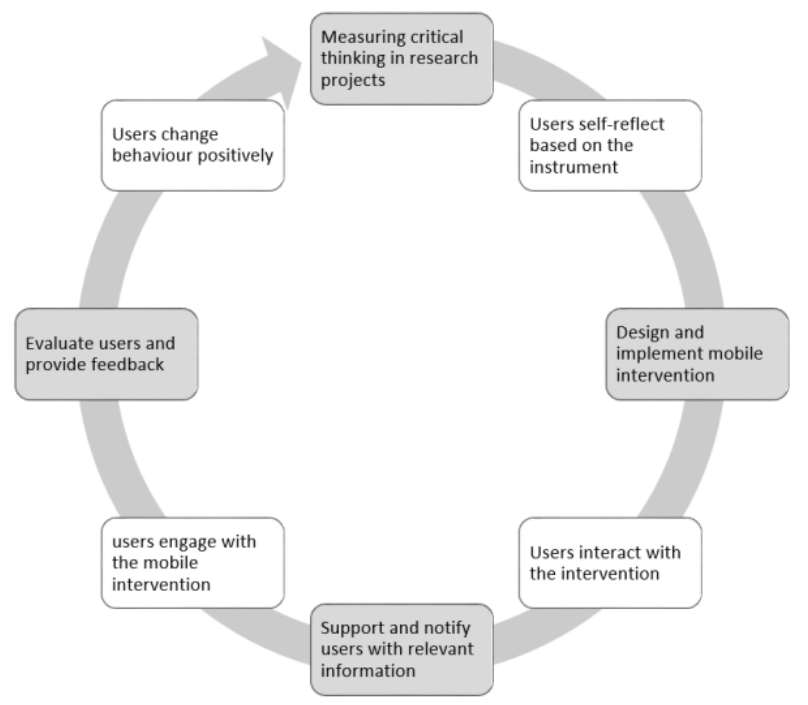

Fig. 2. DBCIs intervention cycle.

A two-group experimental study was conducted for measuring critical thinking skills before and after an $\mathrm{mBCI}$ was used in a 3rd-year research project context for two months (Table II). Before this experiment, each requirement for conducting this study was determined, such as the design of the intervention surveys (Table I) to measure critical thinking skills in the context of $\mathrm{mBCI}$ use. Based on the results of previous research, the final version of the instrument was improved in terms of validity and reliability. Additionally, the $\mathrm{mBCI}$ was redesigned based on feedback provided in the interviews by academic supervisors. The iSurvey was utilized to design the pre- and post-intervention surveys. Verification of the usability and functionality of the mobile application used was performed over a 3-day pilot study which involved independent participants. Participant recruitment was performed via invitation emails which contained a consent form. The data were collected and analyzed, including formative assessments by academic supervisors.

\section{B. Participants and Procedures}

Three types of participants were recruited. Firstly, by using the snowball sampling technique, 3rd-year undergraduate students from the University of Southampton's Electronics and Computer Science (ECS) department were approached; they were selected because of the researcher's familiarity with research topics in this department [56] which is aimed at possible participants through participants who are already enrolled. Secondly, academic supervisors were targeted from

TABLE II

Experimental Phases for Control and Intervention Groups

\begin{tabular}{l|c|c}
\hline \hline & $\begin{array}{c}\text { Intervention } \\
\text { group }\end{array}$ & $\begin{array}{c}\text { Control } \\
\text { group }\end{array}$ \\
\hline $\begin{array}{l}\text { Self-assessment for critical thinking before the } \\
\text { experiment by the instrument (Table I). }\end{array}$ & $\sqrt{ }$ & $\sqrt{ }$ \\
$\begin{array}{l}\text { Interaction with the mobile app for intervention } \\
\text { components for two months. }\end{array}$ & $\sqrt{ }$ & $\sqrt{ }$ \\
Receiving normal feedback from supervisors. & $\sqrt{ }$ & $\sqrt{ }$ \\
$\begin{array}{l}\text { Receiving real-time feedback from intervention } \\
\text { creators thorough the mobile intervention. }\end{array}$ & $\sqrt{ }$ & $\sqrt{ }$ \\
$\begin{array}{l}\text { Self-assessment for critical thinking after the } \\
\text { experiment by the instrument (Table I). } \\
\begin{array}{l}\text { Evaluating critical thinking using the mobile } \\
\text { app texts by experts. }\end{array}\end{array}$ \\
$\begin{array}{l}\text { Evaluating critical thinking using the students' } \\
\text { reports by experts. }\end{array}$ & $\sqrt{ }$ & $\sqrt{ }$ \\
\hline \hline
\end{tabular}

the University of Southampton's Computer Science and Education faculties to assess participants' work, such as the project reports. Thirdly, post-doctoral fellows at the ECS acted as experts to assess students' work (texts from mobile use).

The recruitment process involved identifying Electronics and Computer Science undergraduate students who were participating in third-year research projects. Undergraduate research projects usually happen over one academic year (9 months). This study focuses on the 1st semester of the research projects. Students were recruited using a list of emails of 3rdyear undergraduate students. There are restrictions to using university email lists and only the research project leader has access. Emails were targeted and distributed to research project leaders of 3rd-year ECS undergraduates which included the study title, the study's purpose, and the pre- intervention survey. A participant information sheet was included in the preintervention survey, after which the participants could enter their email address into a text box. Participants were separated 
randomly into two balanced groups: the first was the intervention group, and the second was the control.

60 participants filled in the pre-intervention survey before participating in the $\mathrm{mBCI}$ study, they were divided randomly into control and intervention groups with each consisting of 30 participants. An independent Student's t-test was applied to identify significant differences between each group. Participants responded using a 5-point Likert scale to the preintervention survey (Table I) to evaluate their perceived skills in performing critical thinking skills linked to the following variables: the intellectual standards; including accuracy, breadth, clarity, depth, fairness, logic, precision, relevance, and significance, and the elements of thought; including assumptions, concepts, implications, inferences, information, point of view, purpose, and questions. The results from the independent Student's t-test, including a comparison of the mean values for each of the intellectual standards and elements of thought, revealed no statistically significant differences $(p<$ .05 ) between each group for any intellectual standard or element of thought before the $\mathrm{mBCI}$ experiment, demonstrating that participants for the two groups exhibited equivalent critical thinking skill levels.

A welcome email was distributed to the intervention group requesting that they also participate in the mobile intervention experiment by installing a mobile application from the Apple AppStore or Google Play Store, depending on their model of smartphone. The intervention group participated in the preintervention survey and the $\mathrm{mBCI}$ experiment, which coincided with the two-month period of the research project and the postintervention survey. Conversely, the control group only participated in the pre- and post-intervention surveys. Each group was requested to provide their research report for assessment when the experiment ended. The surveys were comprised of two sections, the intellectual standard statements and elements of thought statements. On the basis of these statements each participant was asked to reflect upon their critical thinking skills using the following 5-point Likert scale: $(\mathrm{No}=1)$, (Sometimes=2), (Not sure=3), (Usually=4), and (Always=5). Participants could add any explanation or comment at the end of each survey into the provided empty text boxes.

The study took place over a period of two months, divided into 10 weeks. Based on the required intervention, mobile notifications were sent to the participants from the mobile intervention group, and included hints and reminders for plans or goals, comments, corrections, supportive information, or feedback. During the final week of the experiment, the intervention group participants were requested to respond to polls to evaluate the usability of the mobile intervention. Notifications were sent twice a week to participants (intervention group) in the form of feedback and nudges, which acted as a reminder to keep participants engaged with the interventions. Feedback was based on users' critical thinking skills and was based their performance in the mobile tasks. The work was evaluated by the researcher from the mobile intervention so that pertinent feedback could be determined. For participants who were not engaged for extended periods, emails were sent to increase engagement. When the experiment was completed, invitations were sent to the previously interviewed academic supervisors to assess the reports submitted by participants. The academic supervisors were all sent emails, including the study title and the reason for the evaluation. After the academic supervisors had agreed to participate, an online form was sent to them. New experts (postdoctoral fellows from the ECS) were requested to evaluate the text inputted by the participants in the mobile app. Additional Google Forms were sent to the experts to evaluate the mobile application inputs and texts.

\section{Data Collection and Analysis}

A mixed-methods approach was used to collect the qualitative and quantitative data. Data were gathered across the entire two-month study period. Four types of data were collected from students, academic supervisors, and experts, as described below:

1) Responses, in the form of quantitative data, to both pre- and post-intervention questionnaires.

2) Using the mobile application, participants can automatically generate $\log$ file data, for example the amount of time spent on each of the pages, the dates on which the mobile intervention was used, users' texts, and responses to the short surveys.

3) The participants' progress reports. Data for the mobile intervention group were collected by obtaining responses from the surveys before and after the intervention, log files demonstrating mobile usage of the application, and project progress reports. Data from the control group were gathered individually by collecting only the responses to the surveys before and after the intervention and progress reports.

The evaluation of the work and progress of participants, performed by academic supervisors and experts, which included both quantitative data and qualitative data. Experts used a 5-point Likert scale to rate and assess the work, which ranged from strongly disagree to strongly agree, the use of the mBCI enhanced students, critical thinking skills in a research project context:

1) The data were analyzed to determine the following factors: Examine any perceived progress and improvement in participant critical thinking skills in the two groups by establishing significant differences, if any, $(p$ values $<.05)$ exist between the two groups before after the experiment. This includes comparisons of self-assessment ratings and formative evaluation by academic supervisors in regard to critical thinking skills.

2) Correlations were identified, for the intervention group, between the amount of time using the mobile intervention and the critical thinking improvements.

3) Specifying which intervention components led to improvements in which intellectual standards or elements of thought by determining the correlations between performance on the elements or standards and the time spent using specific intervention components designated to improve certain standards or elements.

4) Measuring if engagement levels may be credited to notifications by calculating the time spent before and after the notifications are received each week.

5) Analyzing mBCI usability on the basis of user assessment reported via the SUS test survey [58]. The SUS survey test 
is a reliable survey, with Cronbach's alpha $=.91$, to evaluate the usability of a product or system. The SUS test was used for measuring the mobile intervention's usability designed to promote critical thinking in a research project context. The SUS test employs 10 statements on a 5-point scale which range from strongly agree (5) to strongly disagree (1).

\section{DESIGNING INTERVENTION COMPONENTS: LIFEGUIDE TOOLBOX IMPLEMENTATION AND MOBILE CONTENT}

The LifeGuide project launched in 2009 and was created by psychology and computer science researchers at the University of Birmingham, University of Cambridge, and University of Southampton. The UBhave project designed and developed the LifeGuide Toolbox as a mobile extension of the LifeGuide platform. The objective was to develop a software tool to assist researchers with limited programming experience to design DBCIs and create interactive web- or mobile-based content for supporting learners [51], [52]. Researchers used the software primarily in the fields of health and behavioral sciences, which has been successfully used to support changes to health behaviors, such as supporting healthy physical habits, losing weight, smoking cessation, and hand hygiene [13], [53]. The LifeGuide Toolbox was adjusted and facilitated to increase its interactivity and engagement, especially for intervention components which provide feedback or notifications to users and which can get user enquiries, together with an administrator panel for monitoring the interactions between the mobile intervention and users (Fig. 3).

The design and implementation of the DBCI was comprised of two primary components. Firstly, a web-based authoring tool was used to design a mobile intervention with the objective of altering behaviors, for example supporting the critical thinking skills of students in a research project context, with support from an existing LifeGuide Toolbox software tool which was used to conduct the initial DBCI experiments. Secondly, a mobile, application-based intervention, titled the CriticalThinking mobile application (Fig. 4), was designed using the abovementioned tools, included a web-based administrator panel allowing the intervention designer to interact with users by visualizing, tracking, and monitoring work progress. The web-based admin panel was designed to assist the intervention creators with monitoring and downloading user data and managing communications via notifications, delivering supportive content in a real-time feedback, solving questions, and sending and receiving short surveys to assess work and progress of the users. The content of the critical thinking activities in the mobile intervention was adopted from a recent book by Cottrell [57] as shown in Table II.

The intervention components are composed of the essential digital elements enabling users to use the content of the mobile intervention. Interviews with academic supervisors and a literature review were used to identify the components [17], [22]. The specified components were chosen as they were considered to have greater effectiveness in promoting critical thinking as a behavior in a research project context. The intervention components included:

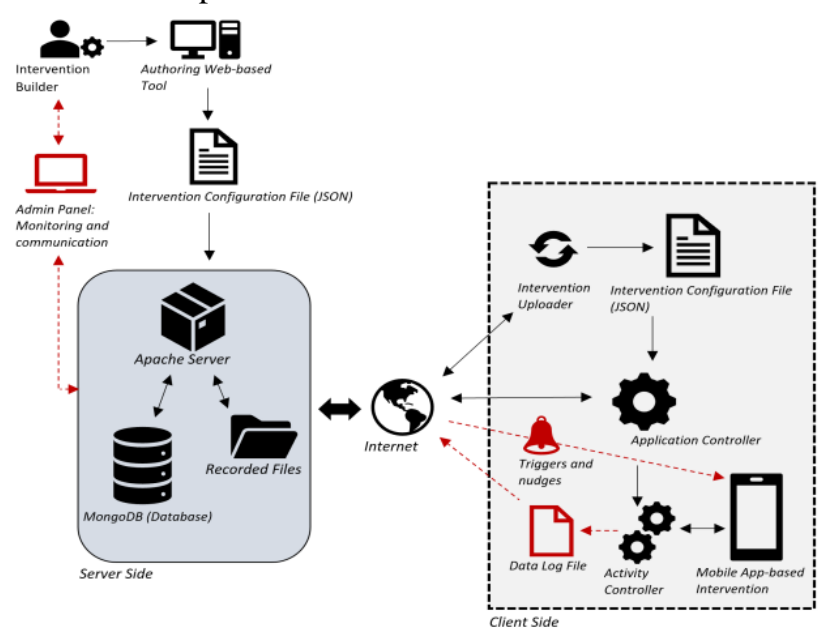

Fig. 3. The integration of LifeGuide toolbox with the mBCI app.

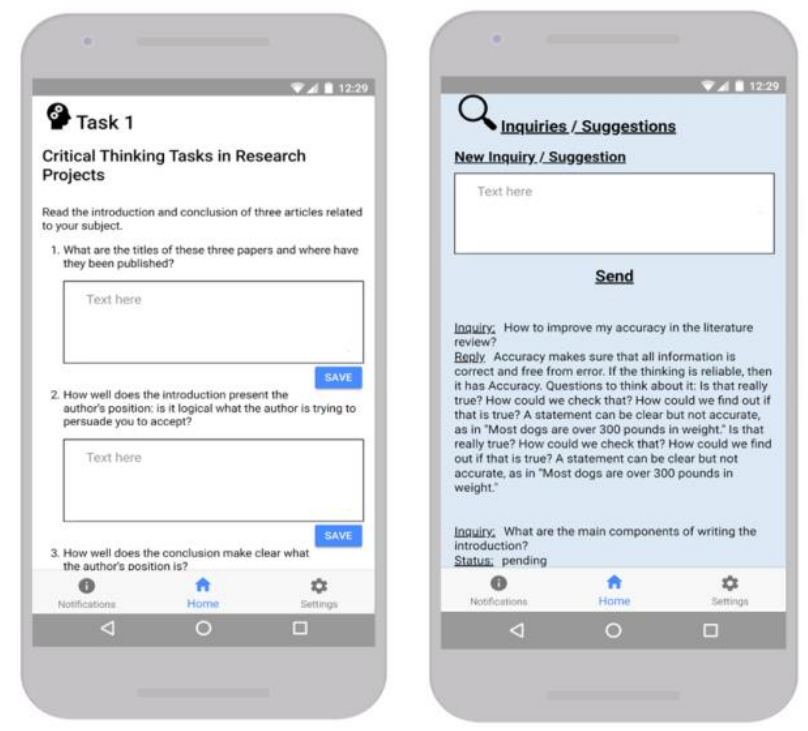

Fig. 4. Mobile CriticalThinking application-based intervention.

1) Project information: The page features questions including What is the nature of the research project, RQs, why, hypotheses, how, and what to expec.t

2) Activities and training: The app instructs users to think about general topics in critical thinking. For example: "The author's position."

3) Practice tasks: the app provides simple passages so that users can practice some concepts of critical thinking. For example, "PRACTICE 1: Capturing the author's position: Read through the following passages and identify the author's position."

4) Short questionnaires: participants are asked to answer short quizzes during the research. For example, "Have you read about the difference between the conference paper and journal paper as sources of information?"

5) Setting goals and plans: Goals are set to improve certain intellectual standards. For instance, improving significance and clarity in writing or organize plans to improve specific critical thinking skills. For example, identifying this 
TABLE III

Activities and Tasks in the Mobile Intervention

\begin{tabular}{|c|c|c|}
\hline $\begin{array}{l}\text { Activities and Tasks (1) for 'what's their } \\
\text { point? Identifying arguments' }\end{array}$ & $\begin{array}{l}\text { Activities and Tasks (2) 'for how well do they say } \\
\text { it? Clarity, consistency and structure' }\end{array}$ & $\begin{array}{l}\text { Activities and Tasks ( } 3 \text { ) 'where's the proof? Finding } \\
\text { and evaluating sources of evidence' }\end{array}$ \\
\hline Mapped with Depth, Breadth, And Logic & Mapped with Clarity, Precision, And Accuracy & Mapped with Significance, Relevance, And Fairness \\
\hline
\end{tabular}

month's book or supervisory meetings.

6) Notifications for engagement: notifications are delivered to students via the app to assist them with relevant information in critical thinking skills.

7) Enquiries and answers and providing feedback and instructions: Participants can ask questions or give feedback on any problems faced in their critical thinking skills. The intervention researcher answers the questions.

Activities and feedback require that users read the intervention content, whereas the other components requested that users make a selection from a range of options (short questionnaires) or via a text-based response (tasks, enquiries, goals and plans, and project information). The components were used in the mobile intervention to assess user responses. The intervention components were connected to intellectual standards and elements of thought (Table III) to gain a better understanding of the components which contributed to enhancing particular critical thinking skills. The effectiveness of the mobile intervention was evaluated by measuring the time taken by users on each component and performing an assessment of the responses to those components.

\section{A. LifeGuide Toolbox Software with A Web-based Authoring Tool}

The LifeGuide Toolbox software package was essentially produced to give designers a tool to create Internet-based interventions to assist the end-user with their undesirable behavior. The LifeGuide Toolbox has various features which allows users to make plans, set goals, and perform particular activities, in addition to answering polls or questionnaires, with no limitation on time and place. These digital tasks help researchers to study user effectiveness in their interactions with the intervention and performing an evaluation of user engagement with the tool [54]. Yet, the LifeGuide Toolbox framework cannot assist intervention builders with communicating with the intervention users. This was alleviated in this study by making the LifeGuide Toolbox more interactive and also by introducing particular intervention components to provide feedback or notifications to users and allowing developers to receive user enquiries, together with a web-based administrator dashboard to observe the interaction between the mobile interventions and the user, as shown (with red color) in Fig. 3.

Additionally, the tool's notification system can accommodate different experiments. The specific design of the tools helps the supervisors, and the students generate multicross applications to effectively communicate and collaborate. The stages required to create a mobile intervention are that: Authors use the authoring tool to design the interventions.

1) A central server hosts the intervention.

2) Participants use a mobile platform to select and download the application (intervention).

3) The intervention design is interpreted by the mobile app and the specified content is then provided.

The following data are embedded in the LifeGuide Toolbox digital intervention. Firstly, intervention data: survey answers, planner entries, and diary entries. Secondly, usage data: this logs detail when the user receives a notification or accesses an activity. Thirdly, sensor data: data from various sensors, including regularly recording information from accelerometers and GPS

The LifeGuide Toolbox features had good suitability as they provided the required tools by which to develop cross-platform applications for critical thinking. The LifeGuide Toolbox includes several beneficial features for this experiment, such as designing educational activities, short surveys, planners, goal setting, and text boxes for notes or diaries. Osmond et al. [55] state that there are many factors which make the LifeGuide Toolbox distinct from other tools, such as a HTML editor and App Inventor, which can be used for designing Internet-based interventions. The LifeGuide Toolbox includes:

1) The design of the LifeGuide Toolbox allows the creation of interactive web pages and complex interventions that can change their content as a reaction to different conditions.

2) The LifeGuide Toolbox creates pages for recording 
participant-generated data, without browsing log files from the server.

3) The LifeGuide Toolbox offers the capability to stratify and randomize users or to use previous participants' data, which creators and authors can use to deliver new content.

4) The LifeGuide Toolbox utilizes a framework for conducting trials and permits multiple visits, required for numerous other interventions.

5) The logic editor is an essential factor of the authoring tool and distinguishes the LifeGuide Toolbox from basic HTML editing software, enabling interventions to develop further than simple static web pages. Authors can use the logic editor to express logic in a natural way that does not necessitate specialist training.

6) There are suggestions for a graphic user pages for the logic, with interfaces in the intervention characterized as arrows and nodes linking pages, which depicts that they can move from one page to another.

\section{RESULTS}

\section{A. Interaction and Engagement with the Mobile Intervention}

The 30 students who responded to the pre-intervention survey were placed in the intervention group and took part in the $\mathrm{mBCI}$. The results in Fig. 5 show the duration taken on the $\mathrm{mBCI}$ and show that the duration in the $\mathrm{mBCI}$ varied depending on the components involved in the interaction, including activities, tasks, short quizzes, project information, plans and goals, answers, enquiries, and feedback, on a weekly basis. Participants took more time to read content than enter text into the mobile application. The results reveal that most of the time taken in the mBCI was spent engaging with the different critical thinking activities which aimed to boost user comprehension and knowledge of critical thinking concepts in a research 2nd and 4th day of every week. In general, the initial notification reminded participants to participate in the intervention components, while the second contained answers to questions or feedback in regard to participants' performance on the critical thinking tasks and enquiries. The total time spent by all participants in the $\mathrm{mBCI}$ was around 855 minutes over the two-month period. During each week, there was a variation in the total time expended over the ten weeks of the experiment.

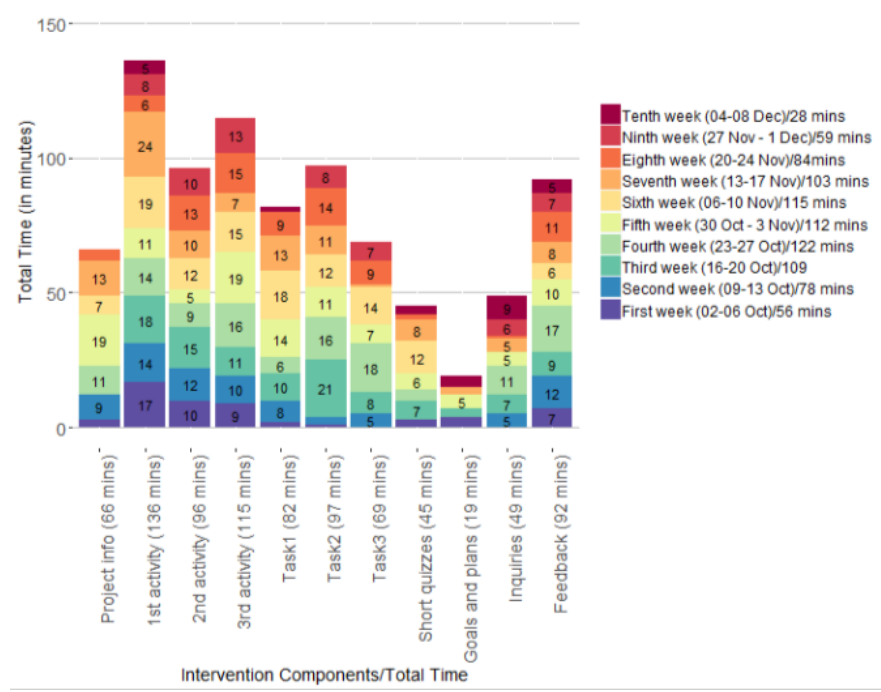

Fig. 5. Total time spent weekly in the mobile intervention components.

The results (Table IV) revealed that each week participants spent their time differently in the mBCI. In the first week, participants took 56 minutes with the $\mathrm{mBCI}$, indicating initially lower engagement levels with the intervention. In the second week, participants increased their engagement with the $\mathrm{mBCI}$ by 22 minutes, showing an increase in participation with the components. The mBCI increased the intervention engagement

TABLE IV

Weekly Interaction and Engagement with the Mobile Intervention Components

\begin{tabular}{|c|c|c|c|c|c|c|c|c|c|c|c|c|}
\hline & $\begin{array}{l}\text { Project } \\
\text { info }\end{array}$ & $\begin{array}{l}1 \text { st } \\
\text { activity }\end{array}$ & $\begin{array}{l}2 \text { nd } \\
\text { activity }\end{array}$ & $\begin{array}{l}\text { 3rd } \\
\text { activity }\end{array}$ & Task1 & Task2 & Task3 & $\begin{array}{l}\text { Short } \\
\text { quizzes }\end{array}$ & $\begin{array}{l}\text { Goals } \\
\text { and } \\
\text { plans }\end{array}$ & Inquiries & Feedback & $\begin{array}{l}\text { Time } \\
\text { in } \\
\text { mins } \\
\end{array}$ \\
\hline $1^{\text {st }}$ week $(02-06$ Oct $)$ & 3 & 17 & 10 & 9 & 2 & 1 & 0 & 3 & 4 & 0 & 7 & 56 \\
\hline $2^{\text {nd }}$ week $(09-13$ Oct $)$ & 9 & 14 & 12 & 10 & 8 & 3 & 5 & 0 & 0 & 5 & 12 & 78 \\
\hline $3^{\text {rd }}$ week (16-20 Oct) & 0 & 18 & 15 & 11 & 10 & 21 & 8 & 7 & 3 & 7 & 9 & 109 \\
\hline $4^{\text {th }}$ week $(23-27$ Oct $)$ & 11 & 14 & 9 & 16 & 6 & 16 & 18 & 4 & 0 & 11 & 17 & 122 \\
\hline $5^{\text {th }}$ week ( 30 Oct- 3 Nov) & 19 & 11 & 5 & 19 & 14 & 11 & 7 & 6 & 5 & 5 & 10 & 112 \\
\hline $6^{\text {th }}$ week $(06-10 \mathrm{Nov})$ & 7 & 19 & 12 & 15 & 18 & 12 & 14 & 12 & 0 & 0 & 6 & 115 \\
\hline $7^{\text {th }}$ week (13-17 Nov) & 13 & 24 & 10 & 7 & 13 & 11 & 1 & 8 & 3 & 5 & 8 & 103 \\
\hline $8^{\text {th }}$ week (20-24 Nov) & 4 & 6 & 13 & 15 & 9 & 14 & 9 & 2 & 0 & 1 & 11 & 84 \\
\hline $9^{\text {th }}$ week $(27$ Nov -1 Dec $)$ & 0 & 8 & 10 & 13 & 0 & 8 & 7 & 0 & 0 & 6 & 7 & 59 \\
\hline $10^{\text {th }}$ week $(04-08 \mathrm{Dec})$ & 0 & 5 & 0 & 0 & 2 & 0 & 0 & 3 & 4 & 9 & 5 & 28 \\
\hline Total in mins & 66 & 136 & 96 & 115 & 82 & 97 & 69 & 45 & 19 & 49 & 92 & 866 \\
\hline
\end{tabular}

project context. Practicing critical thinking components was second on the list of tasks organized by time spent in the mBCI. More time was spent on the tasks and activities than on other components, as there were three tasks and three activities (Fig. 5).

In DBCIs, engagement is a main factor as it determines the level of participatory intervention [59], [60]. The results reveal that $\mathrm{mBCI}$ engagement varies depending on the response of participants to notifications. Participants exhibited various responses to the notifications, which were distributed on the level by using notifications as nudges to maintain engagement with participants. This result was determined by evaluating the time taken in week 3, which was 109 minutes, and in week 4, which was 122 minutes. In week 5, mBCI engagement declined to 112 minutes. Participants were regularly sent notifications in the form of nudges and feedback. The impact of notifications again increased engagement levels in week 6 to 115 minutes. However, in week 7, engagement levels with the $\mathrm{mBCI}$ decreased by 12 minutes. Likewise, in week 8 , only 84 minutes was spent, showing additional decreases in mBCI engagement. 
TABLE V

Participants Satisfaction on Mobile Intervention Components

\begin{tabular}{|c|c|c|c|c|c|c|c|}
\hline Usefulness/satisfaction & Strongly Disagree & Disagree & Neutral & Agree & Strongly Agree & Mean Values & St.D \\
\hline Project info & $27 \%(n=8)$ & $30 \%(n=9)$ & $27 \%(n=8)$ & $13 \%(n=4)$ & $3 \%(n=1)$ & 2.3 & 1.129 \\
\hline Activities and trainings & $10 \%(n=3)$ & $13 \%(n=4)$ & $20 \%(n=6)$ & $30 \%(n=9)$ & $27 \%(n=8)$ & 3.5 & 1.306 \\
\hline Tasks for critical thinking & $27 \%(n=8)$ & $20 \%(n=6)$ & $30 \%(n=9)$ & $20 \%(n=6)$ & $3 \%(n=1)$ & 2.5 & 1.195 \\
\hline Short quizzes progress & $13 \%(n=4)$ & $30 \%(n=9)$ & $36 \%(n=11)$ & $13 \%(n=4)$ & $7 \%(n=2)$ & 2.7 & 1.087 \\
\hline Goals and plans & $33 \%(n=10)$ & $27 \%(n=8)$ & $30 \%(n=9)$ & $10 \%(n=3)$ & $0 \%(n=0)$ & 2.1 & 1.019 \\
\hline Notifications for engagement & $10 \%(n=3)$ & $33 \%(n=10)$ & $27 \%(n=8)$ & $20 \%(n=6)$ & $10 \%(n=3)$ & 2.8 & 1.166 \\
\hline Feedback and instructions & $17 \%(n=5)$ & $3 \%(n=1)$ & $30 \%(n=9)$ & $33 \%(n=10)$ & $17 \%(n=5)$ & 3.3 & 1.29 \\
\hline
\end{tabular}

In week 9, only one hour was spent, and approximately half an hour was spent in the last week in the $\mathrm{mBCI}$, which indicates a continual decline in engagement, beginning in week 7 .

The time spent in each of the components differed on each day. In the first month, participants had greater engagement with the activities; in the second month the participants engaged more with feedback and enquiries. Each week, the participants were notified about particular interventional components. It was discovered that no connection existed between the components in the notifications and the duration of using those components, indicating that the content of the notifications did not affect how participants engaged with the components. Fig. 6 and 7 show the total time expended weekly by participants. The first month showed regular engagement with the $\mathrm{mBCI}$. The second month showed a reduced level of engagement, with increased fluctuation. On any given day, on average, 10 participants engaged with the mBCI. The most time spent with the mBCI by participants was 32 minutes. On some days, complete disengagement was found, indicating that no time was spent with the mBCI by any of the participants, including day three in week five, day five in the eighth week, day five in the ninth week, and one day in the last week. When participants received a notification, the relative level of engagement increased, revealing the positive and encouraging influence of the notification on engagement level with the $\mathrm{mBCI}$.

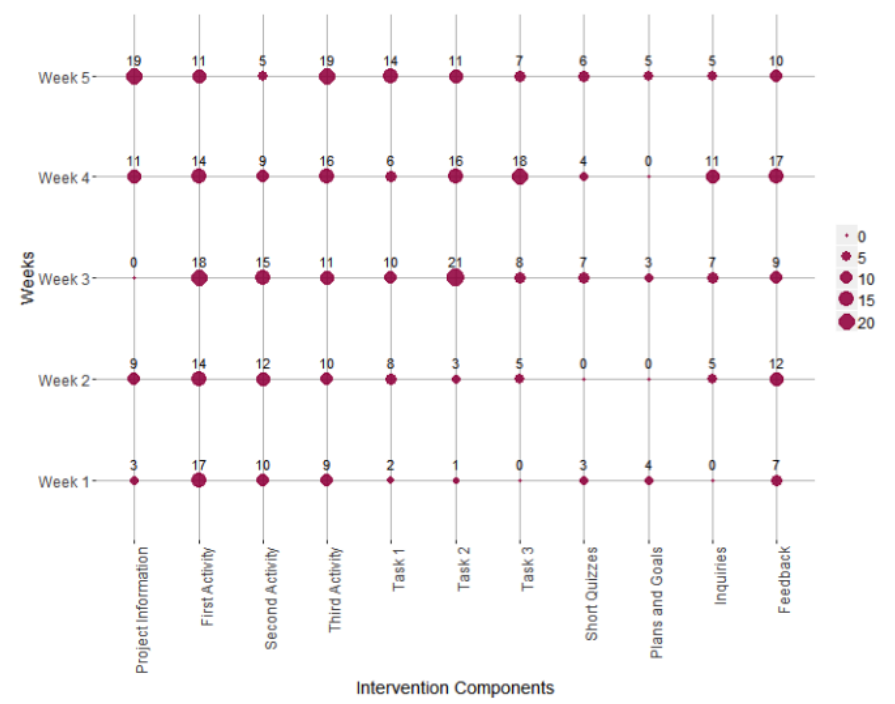

Fig. 6. Engagement with the components in the first month.

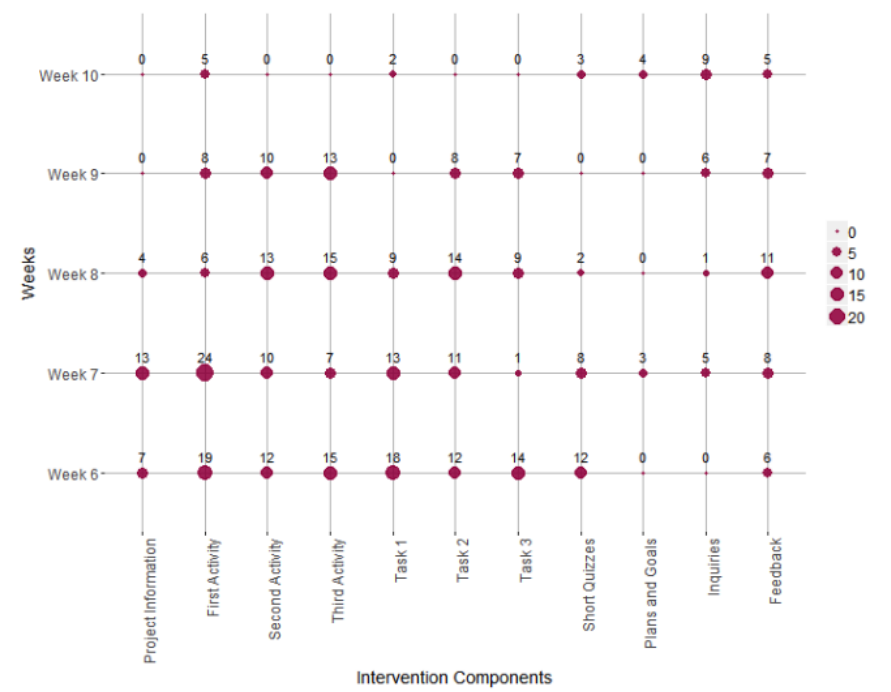

Fig. 7. Engagement with the components in the second month.

\section{B. Usability of the Intervention Components}

The intervention group participants responded to surveys which evaluated the intervention components, including the project information, activities, tasks, short quizzes, goals and plans, notifications, enquiries, and feedback, after using the mBCI for 2 months.

The survey results reveal that participants had positive experiences using these components to improve their critical thinking skills in a research project context. Participant reflections on using these components showed that they were simple to use and that they thought they were useful in the support of critical thinking skills in a research project context. The results showed different reflections from the participants with the intervention components in regard to their mobile learning experiences. Table V shows that $57 \%$ of participants found activities to be helpful for learning about critical thinking (the sum of Strongly Agree and Agree categories), while only $10 \%$ found goals and planning to be helpful and useful components. $36 \%$ of participants had a neutral view with regards to the usefulness of polls (short quizzes). Negative views of participants were found (the total of the Disagree and Strongly Disagree categories) on goals and plans (60\%), project information (57\%) and tasks (47\%), and notifications (43\%).

Participants made a small number of suggestions when the survey ended. For example, participant P14 suggested that it would be a good idea to support the mobile intervention by using a website. Participant P25 suggested that tutorial videos could be useful for learning more about critical thinking.

\section{Formative Assessments by Academics and Self-reflections}

Research reports were shared by 13 participants, 5 from the 
control group and 8 from the intervention group (Fig. 8). The following two approaches were used to assess the reports. Firstly, 3 academic professors were sent the documents, together with the Google Forms assessment sheet. In general, participants in both groups received low assessment ratings from academic professors for critical thinking standards 9. For example, the total score for the self-assessment of participant (P2) across all standards was overrated compared to the total score for participant (P2) given by the academic professors. Similar patterns were found for participant (P102) in the control group. Based on the provided reports, no difference was found between the two groups, two participants (P5 and P23) from the intervention group and one participant (P109) from the control group more closely assessed themselves to the assessments made by academic professors.

Comments by academics referred to the lack of critical thinking skills in the literature reviews:
In their research reports, the intervention and the control groups revealed a similar level of critical thinking skills. No major differences were discovered in terms of the assessed intellectual standards. Some of the observations were made after reviewing the submitted reports from the two groups. Firstly, the intervention group research reports contained specific words that were provided in the mobile intervention. Additionally, the reports had a greater likelihood of following clear steps that explained what the research problem was and how it could be studied. For instance, response from participant (P09) revealed that the written sentences focused on clarity when the project's purpose was explained. The expert assessments showed in the experiment that the participants lacked critical thinking skills, which may be because the participants did not provide sufficient research project data or did not apply the critical thinking skills they learned during the experiment.

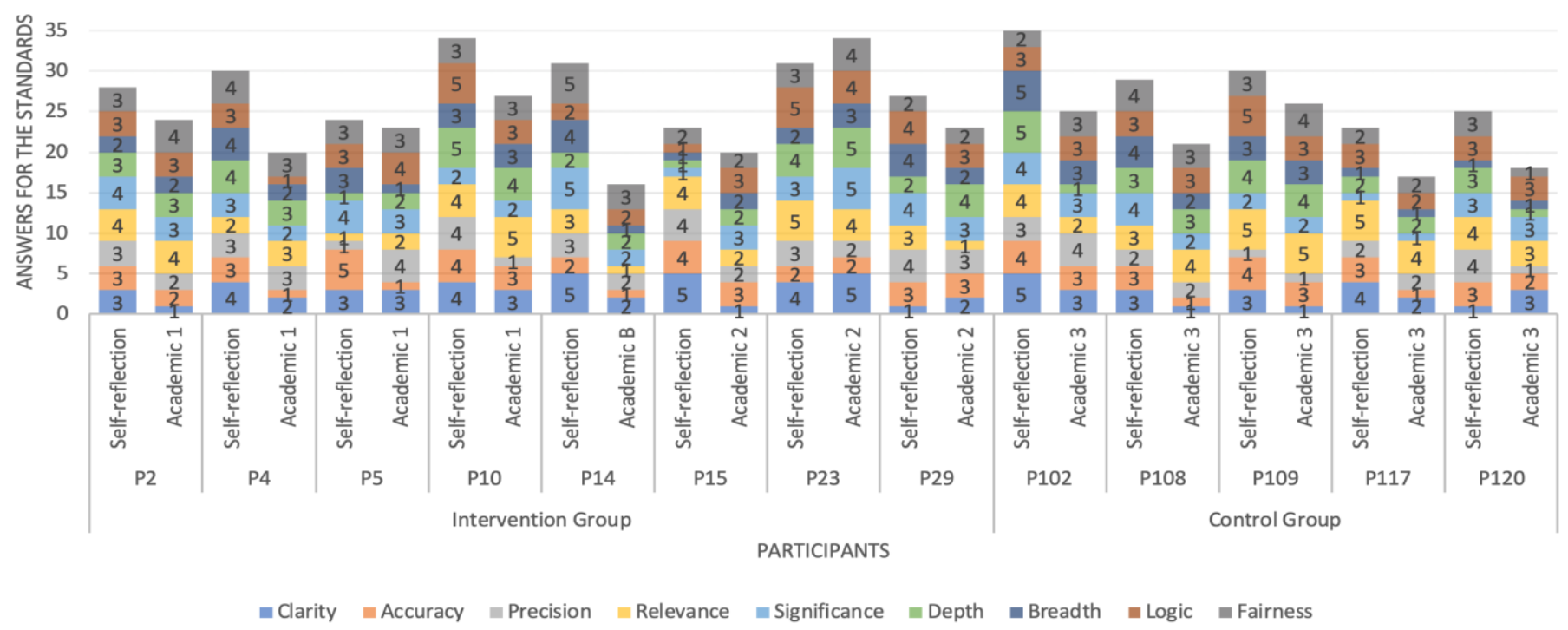

Fig. 8. Formative assessments by academics and self-reflections for both groups.

"A good literature review should review the study methods, in order to justify their use. This was not done in this report. There was no reference to a literature review." (Academic 1 on [P4])

"The research did not describe or define similar studies, which would have revealed gaps in the knowledge, which this work attempts [to fill]." (Academic 3 on [P117])

Other examples revealed a lack of precision and accuracy in some of the reports:

"It was not described how the defined hypothesis would be tested and validated." (Academic 2 on [P10])

"The report lacks a strong theoretical background evaluation supporting or opposing the position of the researcher; additional work is required in this area. The report did not indicate the evaluation methods from which the qualitative and quantitative data are to be obtained from system testing." (Academic 1 on [P14])

A lack of clarity was also found:

"The study lacks focus. [It] is difficult to understand the student's research direction. What would be the outcome of this direction?" (Academic 3 on [P108]).

\section{DISCUSSION}

The evaluation of using a DBCI to promote critical thinking skills in a research project context has led to several conclusions. Firstly, the overall results showed that students still required support for their critical thinking skills when working on a research project, as found in other studies [14], [19]. It is difficult to assess critical thinking skills by the measurement of improvements over time [61]. Some research has relied only on participants' subjective assessments; others have used more objective, expert assessments to review works based on rubrics or specific criteria. Here, both assessment methods and measurement of critical thinking skills were included. The results of self-reflection by participants on their improvements did not align with assessment results from academic professors and experts. The objective assessments made by the academic professors and experts of the students' research projects found that fewer improvements were made in critical thinking skills compared to the students' subjective selfreflective assessments. Alnuaim et al. [62] also addressed this discrepancy, revealing that students occasionally over or 
underestimate their acquisition abilities of critical thinking skills.

Secondly, the time spent with a DBCI to calculate engagement levels with the DCBI was suggested by Yilmaz and Keser [3]. Here, the duration taken in the mBCI was relatively less than the time spent in the relevant studies. The experiment's length may have led to lower engagement with the $\mathrm{mBCI}$. Critical thinking was a behavioral factor and took longer to learn. For all participants, the overall critical thinking scores in the post-intervention surveys modestly correlated $(\mathrm{r}=0.65)$ with the total time spent in the mBCI as shown in Fig. 9. However, the calculated times spent in specific activities and tasks within the mBCI did not significantly correlate with improvements in the specific intellectual standards and elements of thought onto which those activities and tasks were designed to map. There was mutual interaction of critical thinking standards and elements, it was therefore impractical to support them separately through individual components; this explains the insignificant correlation observed between the time spent in intervention components and improvements to the intellectual standards and elements of thought supported by those components.

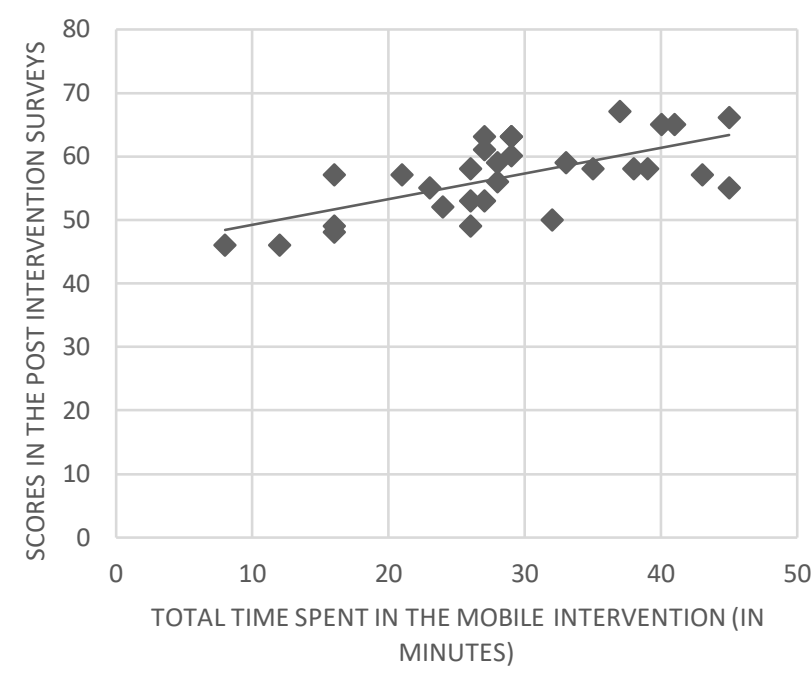

Fig. 9. Correlation between the overall critical thinking scores in the postintervention surveys with the total time spent in the $\mathrm{mBCI}$.

Thirdly, in this study there was a relative increase in mBCI engagement which was revealed by providing feedback through mobile notifications designed to maintain participant engagement; this was particularly associated with their research projects. The weekly comments and feedback provided to the students by the researcher also seemed to lead to improvements in critical thinking skills. Other studies have reported similar results which address the importance of feedback to enhance critical thinking skills [63], [64]. It was strongly suggested by academic professors that feedback be used as an intervention component in the interviews. The results indicated that mobile notifications improved participant $\mathrm{mBCI}$ engagement. In the first weeks, engagement levels with the $\mathrm{mBCI}$ were low as a result of unfamiliarity with the mBCI. Another potential reason for low engagement is that participants were only just beginning their research projects and that they may have preferred to wait until they had a clearer idea of their topic. After the initial three weeks had elapsed, participants started to respond to the notifications by increasing their use with the mBCI. Engagement levels remained stable, with a few fluctuations, until the final 3 weeks, which showed that there was an element of disengagement with the $\mathrm{mBCI}$, possibly because these weeks were busy for students who were taking final exams and submitting research reports. The disengagement with web- or mobile-based DCBIs designed to improve critical thinking skills was addressed in several studies, for example Heflin et al. [65]. Finally, the usability test results and participants' reflection of the intervention components of the $\mathrm{mBCI}$ were encouraging and positive. The tasks, activities, and feedback as intervention components were useful to support critical thinking skills in a research project context, as reported by other studies [64]. Yet, the setting of goals and plans were not considered helpful for enhancing critical thinking skills.

\section{CONCLUSION}

The main aim of this study was to determine the impact of using an $\mathrm{mBCI}$ with real-time feedback to support the critical thinking skills of 3 rd year students in a research project. The study examined the perceived abilities of students in using critical thinking skills, both prior to and after the intervention compared to reviews by experts. The $\mathrm{mBCI}$ included intervention components which were designed to support the critical thinking behavior of students, for example, working on research tasks and activities, organizing the work using goals and plans, answering short questionnaires, and receiving notifications containing feedback and answers to use enquiries. Students received notifications which contained targeted advice and tailored information. Combining the LifeGuide Toolbox software and the Paul-Elder Critical Thinking Framework has improved some of the perceived critical thinking skills students in a research project context; however, the independent expert review did not support the self-reported improvements. It can be also concluded that mobile notifications increased $\mathrm{mBCI}$ engagement and interaction. Digital mBCIs can be used by students to obtain supportive assistance for their critical thinking skills as required, irrespective of place and time, which could be a cost-effective way to facilitate communication between supervisors and students. Using the existing LifeGuide Toolbox framework to create mBCIs to assist critical thinking skills could be successful as it consists of an authoring tool enabling intervention builders who do not have a background in programming to simply create digital interventions. Consequently, the tool could be used by many scientists and researchers to provide them with the required data of students critical thinking behaviors during a research project.

This study contributes to the body knowledge by: a) developing design principles to implement and test engaging digital mBCIs to enhance critical thinking skills in a research project context; and $b$ ) the impact of engaging with intervention components to improve specific critical thinking standards and studying and evaluating various elements. To the best of our knowledge, there is no generic framework which has used DBCIs to assess feedback, measuring and supporting critical thinking skills in a research project context. Thus, supervisors and educators must be provided with an authoring tool which 
can be used to design and deploy digital interventions for students in research projects with real-time feedback interaction, provision, and personalization. This tool would assist those who create interventions, for example, supervisors, with developing digital interventions for users in various contexts. When they require assistance, students can get responsive assistance to develop their critical thinking skills and competency with digital interventions via smartphones, regardless of time or place. In a supervisory research capacity, this may be a cost-effective process for both students and supervisors.

This research can form the base for instructors, eLearning designers, educators and policy makers in education to change university students' undesirable behaviors, not only in research projects and critical thinking but also in other learning areas. In fact, many of the skills required for learning, such as teamwork, time management, and attending lectures, may be able to be improved and promoted through the provision of tested methods and robust tools in the form of mBCIs. Using the DBCI can assist with identifying critical thinking weaknesses requiring support at an early stage, which can be of benefit to supervisors. The currently proposed system allows supervisors the flexibility to design reusable complex interventions, deliver tailored information to users on a large scale, and to monitor and measure critical thinking progress in research projects. Similarly, students can also benefit from the system where they can learn new skills, ask questions, and reflect on their progress throughout their research projects.

Several suggestions are recommended for future research in using digital behavior change interventions to support and improve critical thinking skills. The two suggested areas for further research are (1) developing and implementing $\mathrm{mBCI}$ tools and (2) the study design factors based on the studies conducted in this research. For mBCI development, addition of an auto-notification system for nudges and utilizing machine learning techniques is recommended, and users could be provided with the chance to specify their notification preferences based on time and location. Using machine learning (ML) techniques helps to find the best time and locations to notify with prober content. For the study design, different disciplines are suggested which could be included to extend the study's implications. Moreover, students at different levels, such as master's students, can be recruited for experimental research. Including more types of students may necessitate that experiments focus on specific standards, elements or components, instead of supporting all of them. Further studies might include particular stages of the research project (e.g., the methodology or data analysis stages) to draw a more accurate conclusion.

\section{REFERENCES}

[1] R. H. Ennis, "Critical thinking across the curriculum: A vision," Topoi, vol. 37, no. 1, pp. 165-184, Jun. 2018, doi: 10.1007/s11245-016-9401-4.

[2] A. Carpi, D. M. Ronan, H. M. Falconer, and N. H. Lents, "Cultivating minority scientists: undergraduate research increases self-efficacy and career ambitions for underrepresented students in STEM," J. Res. Sci. Teaching, vol. 54, no. 2, pp. 169-194, Aug. 2016, doi: 10.1002/tea.21341.
[3] F. G. K. Yilmaz and H. Keser, "The impact of reflective thinking activities in e-learning: A critical review of the empirical research," Comput. Educ., vol. 95, pp. 163-173, Apr. 2016, doi: 10.1016/j.compedu.2016.01.006.

[4] V. Devi, R. R. Abraham, and U. Kamath, "Teaching and assessing reflecting skills among undergraduate medical students experiencing research,” J. Clin. Diagnostic Res., vol. 11, no. 1, JC01-JC05, Jan. 2017, doi: 10.7860/JCDR/2017/20186.9142.

[5] H. L. dos Santos and C. Cechinel, "The final year project supervision in online distance learning: Assessing students and faculty perceptions about communication tools," Behav. Inf. Technol., vol. 38, no. 1, pp. 65-84, Aug. 2018, doi: 10.1080/0144929X.2018.1514423.

[6] L. S. Behar-Horenstein and L. Niu, "Teaching critical thinking skills in higher education: A review of the literature," J. College Teaching Learn., vol. 8, no. 2, pp. 25-41, Feb. 2011, doi: 10.19030/tlc.v8i2.3554.

[7] A. Ismail, A. Masek, S. Hashim, I. M. Ismail, M. E. Ismail, and N. D. M. Amin, "The Relationship between student's characteristic and effective supervision: The case of industrial-based project," in Proc. IEEE Int. Conf. Engineering Education, Kanazawa, Japan, Nov. 9-10, 2017, pp. 132-136, doi: 10.1109/ICEED.2017.8251180.

[8] T. Clear, "Supervision for critical thinking: Challenges and strategies," ACM Inroads, vol. 5, no. 4, pp. 26-27, Dec. 2014, doi: 10.1145/2667234.

[9] H. Seifi, H. Halbert, and J. McGrenere, "Supervisor-student research meetings: A case study on choice of tools and practices in computer science," Graph. Interface, vol. 1, no. 1, pp. 129-135, May 2014, doi: 10.1201/9781003059325-17.

[10] A. Brew and L. Mantai, "Academics' perceptions of the challenges and barriers to implementing research-based experiences for undergraduates," Teaching High Educ., vol. 22, no. 5, pp. 551-568, Jan. 2017, doi: 10.1080/13562517.2016.1273216.

[11] J. Buckley, T. Archibald, M. Hargraves, and W. M. Trochim, "Defining and teaching evaluative thinking: Insights from research on critical thinking," Amer. J. Eval., vol. 36, no. 3, pp. 375-388, May 2015, doi: 375388, 2015, 10.1177/1098214015581706.

[12] M. Haghparast, F. H. Nasaruddin, and N. Abdullah, "Cultivating critical thinking through e-learning environment and tools: A Review," Procedia Social Behav. Sci., vol. 129, pp. 527-535, May 2014, doi: 10.1016/j.sbspro.2014.03.710.

[13] C. Hargood, D. Michaelides, M. Weal, V. Pejovic, M. Musolesi, L. Morrison, and L. Yardley, "The UBhave framework: Developing dynamic mobile applications for digital behavioural interventions," in Proc. Int. Conf. Mobile and Ubiquitous Syst.: Comput., Netw. and Services, London, U.K., Dec. 2-5, 2014, pp. 02-05.

[14] A. Alnuaim, P. Caleb-Solly, and C. Perry, "Evaluating the effectiveness of a mobile location-based intervention for improving human-computer interaction students' understanding of context for design," Int. J. Mobile Human Comput. Interact., vol. 6, no. 3, pp. 16-31, May 2014, doi: 10.4018/ijmhci.2014070102.

[15] N. A. Razzak, "Strategies for effective faculty involvement in online activities aimed at promoting critical thinking and deep learning," Educ. Inf. Technol., vol. 21, no. 4, pp. 881-896, Jul. 2016, doi: 10.1007/s10639014-9359-z.

[16] R. Swart, "Critical thinking instruction and technology enhanced learning from the student perspective: A mixed methods research study," Nurse. Educ. Pract., vol. 23, pp. 30-39, Mar. 2017, doi: 10.1016/j.nepr.2017.02.003.

[17] Y. Asiri, D. Millard, and M. Weal, "Digital mobile-based behaviour change interventions to assess and promote critical thinking and research skills among undergraduate students," in Proc. Interact. Mobile Communication, Technol. Learn., Thessaloniki, Greece, Nov. $30^{\text {th }}-$ Dec. $1^{\text {st }}, 2017$, pp. 155-166, doi: 10.1007/978-3-319-75175-7_17.

[18] R. G. Saade, D. Morin, and J. D. Thomas, "Critical thinking in e-learning environments," Comput. Human Behav., vol. 28, no. 5, pp. 1608-1617, 2012, doi: 10.1016/j.chb.2012.03.025. 
[19] H. Al-Mubaid and S. Bettayeb, "Intervention-based method for improving learning and critical thinking," in Proc. Computing. Conf., London, U.K., Jul. 18-20, 2017, pp. 1232-1237, doi: 10.1109/SAI.2017.8252247.

[20] R. Paul and L. Elder, Critical Thinking: Tools for Taking Charge of Your Professional and Personal Life, London, U.K.: Pearson Educ., 2013.

[21] C. Pinder, J. Vermeulen, B. R. Cowan, and R. Beale, "Digital behaviour change interventions to break and form habits," ACM Trans. Comput. Human Interact., vol. 25, no. 3, pp. 1-66, Jun. 2018, doi: $10.1145 / 3196830$.

[22] Y. Asiri, D. Millard, and M. Weal, "Evaluating the impact of the components of a mobile behavior change intervention to support critical thinking in research projects," in Proc. Mobile Learning. Conf., Int. Association for Development of the Information Society, Utrecht, The Netherlands, Apr. 11-13, 2019, pp. 65-72, doi: 10.33965/ml2019_201903L009.

[23] A. Wilde and E. Zaluska, "Held-by-hand learners: A survey of technologies to support positive behaviours of higher education students today," in Tecnología, Innovación e Investigación en los Procesos de Enseñanza-Aprendizaje, Oct. 2016, pp. 3122-3132.

[24] M. M. Grant, "Difficulties in defining mobile learning: Analysis, design characteristics, and implications," Educ. Technol. Res. Develop., vol. 67, no. 2, pp. 361-388, Jan. 2019, doi: 10.1007/s11423-018-09641-4.

[25] I. S. H. Wai, S. S. Y. Ng, D. K. Chiu, K. K. Ho, and P. Lo, "Exploring undergraduate students' usage pattern of mobile apps for education," $J$. Librarianship Inf. Sci., vol. 50, no. 1, pp. 34-47, Aug. 2018, doi: 10.1177/0961000616662699.

[26] T. Cardoso and R. Abreu, "Mobile learning and education: Synthesis of open access research," in Handbook of Mobile Teaching and Learning, Y. Zhang and D. Cristol, Eds., Berlin, Germany: Springer-Verlag, 2015, pp. 1-13, doi: 10.1007/978-3-642-41981-2_85-1.

[27] J. Lee and H. Choi, "What affects learner's higher-order thinking in technology-enhanced learning environments? The effects of learner factors," Comput. Educ., vol. 115, pp. 143-152, Dec. 2017, doi: 10.1016/j.compedu.2017.06.015.

[28] S. M. Salleh, Z. Tasir, and N. A. Shukor, "Web-based simulation learning framework to enhance students' critical thinking skills," Procedia Social Behav. Sci., vol. 64, pp. 372-381, Nov. 2012, doi: 10.1016/j.sbspro.2012.11.044.

[29] M. Alrasheedi, L. F. Capretz, and A. Raza, "A systematic review of the critical factors for success of mobile learning in higher education (university students' perspective)," J. Educ. Comput. Res., vol. 52, no. 2, pp. 257-276, Mar. 2015, doi: 10.1177/0735633115571928.

[30] E. J. Stupple, F. A. Maratos, J. Elander, T. E. Hunt, K. Y. Cheung, and A. V. Aubeeluck, "Development of the critical thinking toolkit (CriTT): A measure of student attitudes and beliefs about critical thinking," Thinking Skills Creativity, vol. 23, pp. 91-100, Mar. 2017, doi: 10.1016/j.tsc.2016.11.007.

[31] M. Norouzi, A. Samet, and R. S. B. Sharifuddin, "Investigate the effect of mobile learning over the critical thinking in higher education," $A d v$. Natural Appl. Sci., vol. 6, no. 6, Jul. 2013, pp. 909-916.

[32] K. Kim, P. Sharma, S. M. Land, and K. P. Furlong, "Effects of active learning on enhancing student critical thinking in an undergraduate general science course," Innovative Higher Educ., vol. 38, no. 3, pp. 223 235, Sep 2012, doi: 10.1007/s10755-012-9236-x.

[33] S. Voelkel, L. V. Mello, and T. Varga-Atkins, "Supporting students during their undergraduate research projects using audio recordings," Innovations Educ. Teaching Int., vol. 55, no. 4, pp. 433-440, Dec. 2016, doi: 10.1080/14703297.2016.1263233.

[34] M. W. Vereijken, R. M. van der Rijst, J. H. van Driel, and F. W. Dekker, "Novice supervisors' practices and dilemmatic space in supervision of student research projects," Teaching Higher Educ., vol. 23, no. 4, pp. 522-542, Dec. 2017, doi: 10.1080/13562517.2017.1414791.

[35] M. A. Bakar, N. Jailani, Z. Shukur, and N. F. M. Yatim, "Final year supervision management system as a tool for monitoring computer science projects," Procedia Social Behav. Sci., vol. 18, pp. 273-281, May 2011, doi: 10.1016/j.sbspro.2011.05.039.

[36] R. Ennis, "Critical thinking across the curriculum: the wisdom CTAC program," Inquiry, vol. 28, no. 2, pp. 25-45, Jul. 2013, doi: 10.5840/inquiryct20132828.

[37] M. Barak and A. Levenberg, "Flexible thinking in learning: An individual differences measure for learning in technology-enhanced environments," Comput. Educ., vol. 99, pp. 39-52, Aug. 2016, doi: 10.1016/j.compedu.2016.04.003.

[38] N. L. Novotny, S. J. Stapleton, and E. C. Hardy, "Enhancing critical thinking in graduate nursing online asynchronous discussions," J. Nurse. Educ., vol. 55, no. 9, pp. 514-521, Aug. 2016, doi: 10.3928/0148483420160816-05.

[39] K. Celuch and M. Slama, "Promoting critical thinking and life-long learning: An experiment with the theory of planned behavior," Marketing Educ. Rev., vol. 12, no. 2, pp. 13-22, Oct. 2015, doi: 10.1080/10528008.2002.11488782.

[40] P. A. Ralston and C. L. Bays, "Enhancing critical thinking across the undergraduate experience: an exemplar from engineering," Amer. J. Eng. Educ., vol. 4, no. 2, pp. 119-126, Nov. 2013, doi: 10.19030/ajee.v4i2.8228.

[41] R. Duron, B. Limbach, and W. Waugh, "Critical thinking framework for any discipline," Int. J. Teaching Learn. Higher Educ., vol. 17, no. 2, pp. 160-166, Jan. 2006

[42] S. Michie, L. Yardley, R. West, K. Patrick, and F. Greaves, "Developing and evaluating digital interventions to promote behavior change in health and health care: Recommendations resulting from an international workshop," J. Med Internet Res., vol. 19, no. 6, p.e232, Jun. 2017, doi: 10.2196/jmir.7126.

[43] L. Yardley et al., "Understanding and promoting effective engagement with digital behavior change interventions," Amer. J. Preventive Med., vol. 51, no. 5, pp. 833-842, Nov. 2016, doi: 10.1016/j.amepre.2016.06.015.

[44] M. J. Weal, C. Hargood, D. T. Michaelides, L. Morrison, and L. Yardley, "Making online behavioural interventions mobile," in Digital Research. Conf., Oxford, U.K., Sep. 10-12, 2012.

[45] N. Lathia, V. Pejovic, K.K. Rachuri, C. Mascolo, M. Musolesi, and P. J. Rentfrow, "Smartphones for large-scale behavior change interventions," IEEE Pervasive Comput., vol. 12, no. 3, pp. 66-73, Jul. 2013, doi: 10.1109/MPRV.2013.56.

[46] N. D. Lane et al., "BeWell: A smartphone application to monitor, model and promote wellbeing," in 5th Int. ICST Conf. Pervasive Comput. Technol. Healthcare, Apr. 2012, pp. 23-26, doi: 10.4108/icst.pervasivehealth.2011.246161.

[47] L. Briz-Ponce, A. Pereira, L. Carvalho, J. A. Juanes-Mndez, and F. J. Garca-Pealvo, "Learning with mobile technologies-students' behavior," Comput. Human Behav., vol. 72, pp. 612-620, Jul. 2017, doi: 10.1016/j.chb.2016.05.027.

[48] J. Vainio, K. Kaipainen, and I. Korhonen, "Habit change as a learning process: Design framework for mobile interventions," in IEEE-EMBS Int. Conf. Biomedical and Health Informatics, Valencia, Spain, Jun. 1-4, 2014, pp. 801-804, doi: 10.1109/BHI.2014.6864485.

[49] P. Mooney, J. B. Ryan, B. M. Uhing, R. Reid, and M. H. Epstein, "A review of self-management interventions targeting academic outcomes for students with emotional and behavioral disorders," J. Behav. Educ., vol. 14, no. 3, pp. 203-221, Sep. 2005, doi: 10.1007/s10864-005-6298-1.

[50] F. C. Mace, P. J. Belfiore, and M. C. Shea, "Operant theory and research on self-regulation," Cogn. Develop., pp. 27-50, 1989, doi: 10.1007/9781-4612-3618-4_2.

[51] C. Hargood, D. T. Michaelides, M. J. Weal, L. Morrison, and L. Yardley, "Digital interventions on and off mobile devices," in Digital Futures, Oxford, U.K., Oct. 23-25, 2012.

[52] L. Yardley et al., "Introduction to the LifeGuide: Software facilitating the development of interactive behaviour change Internet interventions," in 
Proc. 23rd Conf. Society for the Study of Artificial Intelligence and Simulation of Behaviour, Edinburgh, U.K., Apr. 5-8, 2009, pp. 32-35.

[53] A. Weston, L. Morrison, L. Yardley, M. Van Kleek, and M. Weal, "Measurements of engagement in mobile behavioural interventions?," in Digital Health Conf., Florence, Italy, May 18-20, 2015, pp. 1-8.

[54] S. Williams, L. Yardley, and G. B. Wills, "A qualitative case study of LifeGuide: Users' experiences of software for developing Internet-based behaviour change interventions," Health Inf. J., vol. 19, no. 1, pp. 61-75, Mar. 2013, doi: 10.1177/1460458212458915.

[55] A. Osmond et al., "Designing authoring tools for the creation of on-line behavioural interventions," in Proc. 5th Int. Conf. e-Social Science., Köln, Germany, Jun. 24-26, 2009, pp. 10-20.

[56] M. N. Marshall, "Sampling for qualitative research," Family. Pract., vol. 13, no. 6, pp. 522-526, Dec. 1996, doi: 10.1093/fampra/13.6.522.

[57] S. Cottrell, Critical Thinking Skills. Effective Analysis, Argument and Reflection, New York, US: Palgrave Macmillan, 2017.

[58] J. Brooke, "SUS: A quick and dirty usability scale," Usability Eval. Industry, vol. 189, no. 194, pp. 4-7, 1996.

[59] M. Kljun, R. Krulec, K. Č. Pucihar, and F. Solina, "Persuasive technologies in m-learning for training professionals: How to keep learners engaged with adaptive triggering," IEEE Trans. Learn. Technol., vol. 12, no. 3, pp. 370-383, Jul.-Sep. 2019, doi: 10.1109/TLT.2018.2840716.

[60] B. Tabuenca, M. Kalz, S. Ternier, and M. Specht, "Stop and think: Exploring mobile notifications to foster reflective practice on metalearning," IEEE Trans. Learn. Technol., vol. 8, no. 1, pp. 124-135, Jan.-Mar. 2015, doi: 10.1109/TLT.2014.2383611.

[61] Y. L. Lee, "Nurturing critical thinking for implementation beyond the classroom: Implications from social psychological theories of behavior change," Thinking Skills Creativity, vol. 27, pp. 139-146, Mar. 2018, doi: 10.1016/j.tsc.2018.02.003

[62] A. Alnuaim, P. Caleb-Solly, and C. Perry, "Enhancing student learning of human-computer interaction using a contextual mobile application," in Computing Conf., London, U.K., Jul. 13-15, 2016, pp. 952-959, doi: 10.1109/SAI.2016.7556095.

[63] S. Hermsen, J. Frost, R. J. Renes, and P. Kerkhof, "Using feedback through digital technology to disrupt and change habitual behavior: A critical review of current literature," Comput. Human Behav., vol. 57, pp. 61-74, Apr. 2016, doi: 10.1016/j.chb.2015.12.023.

[64] R. A. De Kleijn, P. C. Meijer, A. Pilot, and M. Brekelmans, "The relation between feedback perceptions and the supervisor-student relationship in master's thesis projects", Teaching Higher Educ., vol. 19, no. 4, pp. 336349, Nov. 2013, doi: 10.1080/13562517.2013.860109.
[65] H. Heflin, J. Shewmaker, and J. Nguyen, "Impact of mobile technology on student attitudes, engagement, and learning," Comput. Educ., vol. 107, pp. 91-99, 2017, doi: 10.1016/j.compedu.2017.01.006.

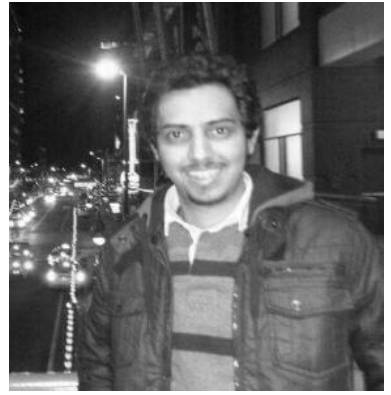

Yousef A. Asiri is an assistant professor in the Computer Science department in Najran University. Yousef is currently the Head of Computer Science Department at Najran University. Yousef is a research member in the Web and Internet Science Group in Electronics and Computer Science at the University of Southampton, U.K. Yousef's main interest is to study how computers affect human behaviors in various aspects such as education, health, and psychology using digital intervention, data analytics, and machine learning.

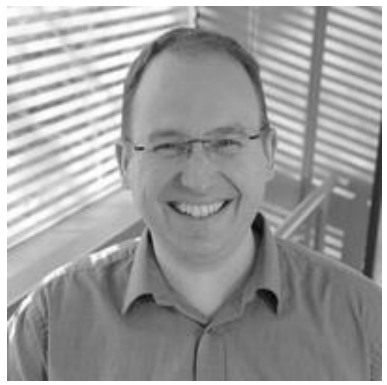

David E. Millard is an associate professor in the Web and Internet Science Group in Electronics and Computer Science at the University of Southampton, U.K. David was involved in Hypertext and Web research for nearly 20 years, firstly in the area of open, adaptive, and contextual hypermedia and later the areas of social media analytics, linked data, UX Design, computational narrative, and Web science. David spent a number of years applying this sort of technology to e-learning, in particular digital literacy, personal-learning systems, and open educational resources (OER).

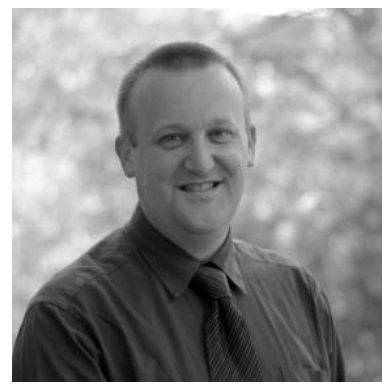

Mark J. Weal is is an associate professor in the Web and Internet Science Group in Electronics and Computer Science at the University of Southampton, U.K. He is the technical lead for the LifeGuide project, a multidisciplinary initiative led by professor Lucy Yardley that has attracted funding of well over $£ 50$ million (from MRC, EPSRC, ESRC, NIHR, EC, and medical charities) for the development of online digital public health interventions such as weight management, hand hygiene, and smoking cessation, as well as illness management interventions including diabetes, cancer, respiratory conditions, and eczema. 